\title{
Predicting lymph node status in patients with early gastric carcinoma using double contrast-enhanced ultrasonography
}

Nianyu Xue', Pintong Huang', Wilbert S. Aronow ${ }^{2}$, Zongmin Wang', Chandra K. Nair ${ }^{3}$, Zhiqiang Zheng', Xuedong Shen ${ }^{3}$, Yimei Yin', Fuguang Huang ${ }^{1}$, David Cosgrove ${ }^{4}$

$1^{\text {nd }}$ Affiliated Hospital of Wenzhou Medical College, Zhejiang, China

${ }^{2}$ Cardiology Division, New York Medical College, Valhalla, NY, USA

${ }^{3}$ Cardiac Center of Creighton University, Omaha, NE, USA

${ }^{4}$ Imaging Sciences Department, Imperial College, Hammersmith Hospital, London, United Kingdom

Submitted: 2 May 2010

Accepted: 31 May 2010

Arch Med Sci 2011; 7, 3: 457-464

DOI: $10.5114 /$ aoms.2011.23412

Copyright (c) 2011 Termedia \& Banach

\section{A bstract}

Introduction: Double contrast-enhanced ultrasonography (DCUS) is a new method we used in predicting lymph node metastasis (LNM) in patients with early gastric cancer.

Material and methods: Seventy-six patients with early gastric cancer diagnosed by gastroscope and confirmed by pathology after operation were examined using DCUS preoperatively. Group N1 included 15 patients with LNM and group NO 61 patients without LNM.

Results: In group N1, 13 patients (87\%) had marked hyperenhancement during early arterial phase using DCUS, and 2 patients (13\%) were unmarked as hyperenhancement. In group N0, 24 patients (39\%) had marked hyperenhancement during early arterial phase using DCUS, and 37 patients (61\%) had unmarked hyperenhancement. The sensitivity and specificity of marked hyperenhancement in predicting LNM in patients with early gastric cancer was $86.7 \%$ and $60.7 \%$ respectively, and the Youden's index was 0.474 . The $\kappa$ value of this method was 0.89 .

Conclusions: Double contrast-enhanced ultrasonography is a new valuable method to evaluate LNM at an early stage of gastric cancer and prognosis of early gastric cancer preoperatively.

Key words: early gastric cancer, lymph node metastasis, contrast-enhanced ultrasonography.

\section{Introduction}

As a result of increased diagnostic accuracy and the wider application of mass surveys, the proportion of early gastric cancer (EGC) among resected gastric cancers has steadily increased, not only in Asia, but also in some Western countries [1-6]. Although the prognosis of EGC is excellent [7-9], EGC with lymph node metastasis (LNM) has a higher possibility of recurrence [10-12]. Because the presence of LNM is the most important prognostic factor for patients with EGC [3, 13-15], radical surgery with extended (D2) lymph node dissection (LND) has become the gold standard treatment for patients with EGC [16-19].
Corresponding author: Wilbert S. Aronow MD Cardiology Division New York Medical College Macy Pavilion, Room 138 Valhalla, NY 10595, USA Phone: 914-493-5311 Fax: 914-235-6274 E-mail: wsaronow@aol.com 
The prevalence of LNM in EGC ranges from $10 \%$ to $20 \%$ [20-24]. Therefore, at least $80 \%$ of patients will undergo unnecessary surgery with D2 lymphadenectomy $[8,25,26]$. Bonenkamp et al. [27] reported that patients with D2 lymph node resection have a higher operative mortality rate with more complications and a longer postoperative hospital stay. Recently, various minimally invasive procedures such as endoscopic mucosal resection and laparoscopic wedge resection without LND have been performed in selected EGC patients to improve the quality of life of long-term survivors [28-35]. For such procedures, the accurate prediction of LNM is crucial to determining the extent of LND.

Although it is extremely useful to know the involvement of lymph nodes before surgery, there is no simple and high sensitivity test to evaluate lymph node status preoperatively. Diagnostic imaging techniques including endoscopic ultrasound (EUS), computed tomography (CT), positron emission tomography (PET) and ultrasonography (US) are still unsatisfactory and do not provide enough evidence for an accurate prediction of metastasis in the regional lymph nodes draining gastric cancer because of their low sensitivity [36-41]. It is also difficult to diagnose such nodes during operation [42]. Because direct detection of LNM with high sensitivity is impossible yet, the indirect assessment of LNM in EGC is still based on the pathobiologic behaviors of the tumor $[19,43]$. Accurate assessment of the pathobiologic behaviors of the tumor needs resected specimens. Biopsies are too superficial to provide the entire information of the tumor [13].

Conventional trans-abdominal US has been considered unsuitable for the detection of early staging lesions and LNM [44]. Oral contrast agent assisted US has been widely used to detect gastric cancer in China. In the present study, we sought to assess LNM of EGC preoperatively using double contrast-enhanced ultrasonography (DCUS), an oral ultrasonic contrast agent combined with an intravenous contrast agent.

\section{Material and methods}

Eighty patients with EGC proven by pathology were examined with DCUS preoperatively between 2005 and 2009 after obtaining written informed consent. Of the 79 patients, 3 were excluded, one with advanced gastric cancer and the other 2 with the number of retrieved lymph nodes less than 15. The remaining 76 patients were enrolled in this study. The mean age of the patients was 58.3 years (range 35-83). The male to female ratio was 1.71 (48/28). Written informed consent was obtained from all patients. The ethics committee for our institution approved the study.
In this study, all patients underwent curative gastrectomy with D2 or more extended (D3) lymphadenectomy for primary early GC. Surgical resections were performed within 3 to 5 days after the DCUS examination. None of the patients in this study received nonsteroidal anti-inflammatory drugs, chemotherapy, radiotherapy, or immunotherapy before surgery. All of the subjects were divided into 2 groups according to their lymph nodes status postoperatively. Group N1 included 15 patients with LNM. Group NO included 61 patients without LNM.

Double contrast-enhanced ultrasonography was performed after fasting for at least $6 \mathrm{~h}$; Atropine sulfate injection $(0.05 \mathrm{mg} / \mathrm{kg})$ was administered via intramuscular injection half an hour before the examination to inhibit gastric peristalsis. An Acuson Sequoia 512 system (Siemens, Mountain View, (A), equipped with a 4V1 vector ${ }^{\mathrm{TM}}$ transducer (frequency: $1.0 \sim 4.0 \mathrm{MHz}$ ) and contrast pulse sequencing (CPS) technology with auto-tracking contrast quantification (ACQ) software was used (Phillips and Gardner 2004).

The oral contrast agent Xinzhang ${ }^{\circledR}$ (Huqingyutang, HangZhou, China) was supplied as a microdot powder which was composed of a kind of soya derivative (48 g per package); it was reconstituted by adding $500 \mathrm{ml}$ of boiling water and gently agitating the water by hand to form a homogeneous particulate suspension.

The distal esophagus of all patients was observed dynamically while the patients ingested the oral ultrasonic agent to expand the stomach and evacuate the air in stomach. Hence, the stomach lumen appeared as an iso-echoic homogenous acoustic window. Then the other parts of the stomach and the duodenal bulb were examined in turns with the patient in different body positions. When a suspected lesion was identified, it was measured routinely. If the lesion was smaller than $5 \mathrm{~cm}$, it would be zoomed in for higher spatial resolution. Then after this procedure, a dynamic real-time contrast-enhanced sonography with CPS mode was performed using the following settings: insonating frequency $1.5 \mathrm{MHz}$ and acoustic power, -15 to $-21 \mathrm{~dB}$. A low mechanical index (0.20) was selected to minimize microbubble disruption. Images of the ideal scanning plane were displayed in a real-time fashion by slightly changing the scanning plane to portray the whole area of the tumor.

Contrast-enhanced sonographic studies were performed after the administration of $2.4 \mathrm{ml}$ of SonoVue (Bracco SpA, Milan, Italy) as a bolus via a 19-gauge peripheral intravenous cannula. The cannula was flushed with $10 \mathrm{ml}$ saline. A timer on the sonography unit was activated at the beginning of injection, and the entire movie sequence (at least 
5 min) was stored on magnetic optical disks for analysis. The contrast study could be repeated a second time if necessary.

The cine loops of the 69 lesions were retrospectively reviewed by 2 independent radiologists who are experts in sonography and microbubble contrast agents. Vascular enhancement of gastric carcinomas was visually classified into 3 patterns: hyper- enhancement, isoenhancement, and hypo-enhancement. Hyperenhancement was defined as a signal intensity over the whole tumor higher than the adjacent normal gastric wall during the whole arterial phase. Isoenhancement was defined as a signal intensity over the whole tumor similar to the adjacent normal gastric wall during the whole arterial phase. Hypoenhancement was defined as a signal intensity over the whole tumor lower than the adjacent normal gastric wall during the whole arterial phase. According to the pattern of enhancement, all cases were classified into the marked hyperenhancement group and the unmarked hyperenhancement group (including hypoenhancement and isoenhancement). The 2 reviewers were unaware of the definitive diagnosis and other imaging information at the time of the analysis. Double contrast-enhanced ultrasonography diagnoses were then compared with the final diagnosis based on the pathologic results.

Lymph nodes were meticulously dissected from the en bloc specimens, and the classification of the dissected lymph nodes was determined by surgeons who reviewed the excised specimens after surgery based on the Japanese Classification of Gastric Carcinoma. The primary tumor and retrieved lymph nodes were fixed in $10 \%$ formaldehyde solution, embedded in paraffin, incised into $4 \mathrm{~mm}$ sections, and mounted on poly-lysine-coated slides. These sections were stained by hematoxylin-andeosin method to confirm their histological diagnosis and other microscopic characteristics. Experienced pathologists were employed to ensure a high quality of pathological diagnosis. The following clinicopathologic variables were evaluated: sex, age, location of tumor (lower third, middle third, upper third, or entire stomach), tumor diameter, histological type (differentiated: well differentiated, moderately differentiated, or papillary; undifferentiated: poorly differentiated, signet-ring cell, or mucinous), LNM, and depth of invasion (mucosa or submucosa).

Sensitivity, specificity and Youden's index were calculated for both oral contrast-enhanced ultrasonography and DCUS. Statistical evaluation was performed using the $\chi^{2}$ test or Fisher's exact test to differentiate the rates among the different groups. Student's $t$-test was used to analyze quantitative data. Kappa statistics was used to show the level of correlation in agreement between the 2 reviewers. Kappa values are categorized as follows [45]. Values between -1 and 0 indicate "no agreement"; between 0 and 0.20 indicate "poor agreement"; between 0.21 and 0.40 indicate "slight agreement"; between 0.41 and 0.60 indicate "fair agreement"; between 0.61 and 0.80 indicate "good agreement"; between 0.81 and 0.90 indicate "very good agreement"; and between 0.91 and 1.0 indicate "excellent agreement". For all analyses, a $p$ value of less than 0.05 was considered statistically significant. All data were analyzed using SPSS13.0 statistical software (Chicago, IL, United States).

\section{Results}

A total of 76 patients who had undergone gastrectomy with D2 or more extended (D3) lymphadenectomy for EGC at the $2^{\text {nd }}$ Affiliated Hospital of Wenzhou Medical College were studied. The number of retrieved lymph nodes in all patients was more than 15, ranging from 15 to 63 (median, 29.9). Lymph node metastasis was detected in 15 patients (19.7\%), and the number of metastatic lymph nodes ranged from 1 to 36 (median 6.9).

In group N1, 13 patients (87\%) had marked hyperenhancement compared with the adjacent normal gastric wall during the early arterial phase by using DCUS (Figure $1 \mathrm{C}$ ), and the other 2 patients (13\%) had unmarked hyperenhancement. However, in group N0, 24 patients (39\%) had marked early hyperenhancement compared to the adjacent normal gastric wall during the arterial phase using DCUS, and the other 37 patients had unmarked hyperenhancement (Figure $2 \mathrm{C}$ ). The sensitivity and specificity of marked hyperenhancement in predicting LNM in patients with early gastric cancer were $86.7 \%$ and $60.7 \%$, respectively, and the Youden's index was 0.474 (Table I). The relationships between pathological characteristics of patients and the type of contrast enhancement are summarized in Table II.

\section{Discussion}

Since LNM remains one of the most important predictors for survival, reduction in lymphadenectomy will probably result in a residue of metastatic lymph nodes [19]. Unnecessarily extended resection will induce a series of complications, which also result in a poor quality of life [10, 46, 47]. Thus, it is important to standardize the optimal extent of LND by investigating LNM of EGC preoperatively.

The low sensitivities of EUS, CT, US and PET are insufficient to allow decision making on the extent of lymphadenectomy [37-40]. Endoscopic ultrasound, MR and CT mainly depend on lymph 

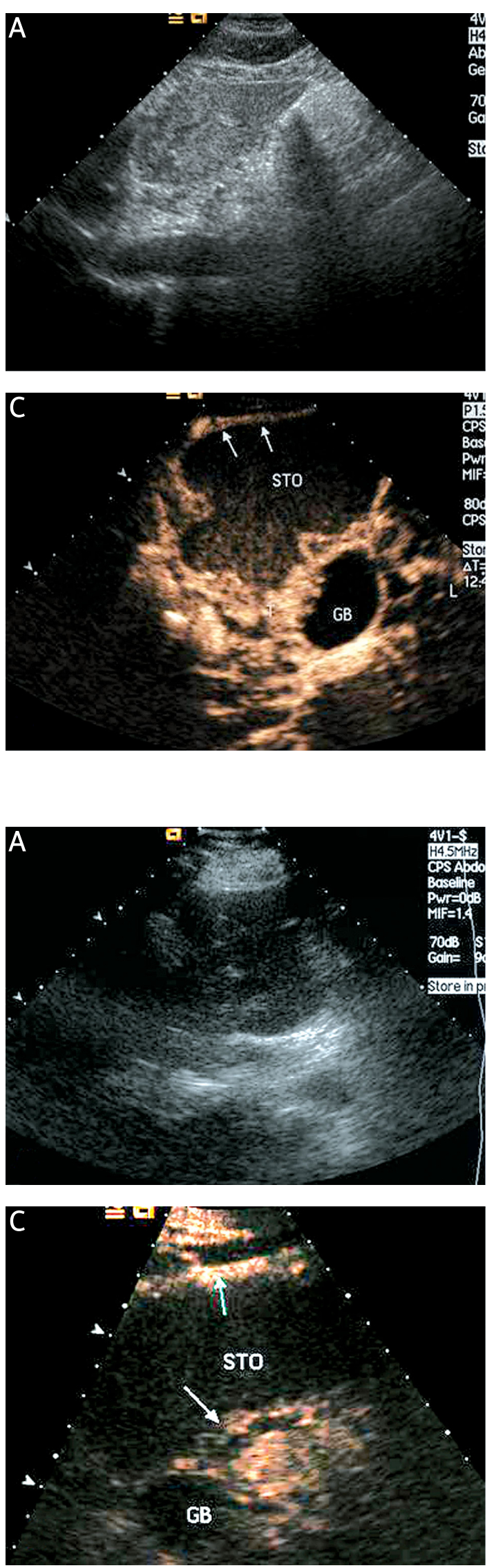

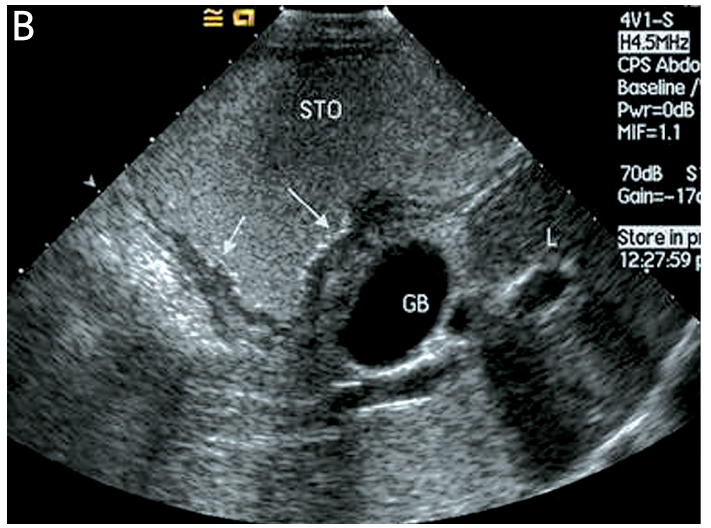

Figure 1. A case of EGC with LNM confirmed pathologically after operation. A: The early gastric cancer and LNM can not be detected with conventional transabdominal US. B: The early gastric cancer (white arrow) can be clearly demonstrated in the oral contrast-enhanced ultrasonography image, but LNM can not be demonstrated. C: Compared with the adjacent normal gastric wall (white arrow), marked hyperenhancement of the EGC (T) in DCUS image was shown during the early arterial phase STO - stomach, $T$ - tumor, GB - gallbladder, L - liver

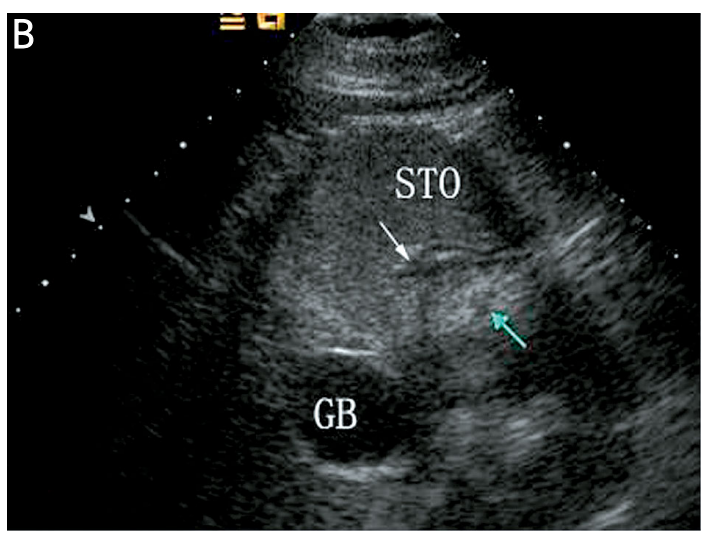

Figure 2. A case of EGC without LNM confirmed pathologically after operation. A: The early gastric cancer and LNM could not be detected with conventional transabdominal US. B: The early gastric cancer (white arrow) and LNM (green arrow) can be clearly demonstrated in the oral contrast-enhanced ultrasonography image. C: Compared with the adjacent normal gastric wall (white arrow), unmarked hyperenhancement of the EGC (green arrow) in DCUS image was shown during the early arterialphase

STO - stomach, GB - gallbladder 
node size as criteria to define malignancy [48]. Lymph nodes of less than $5 \mathrm{~mm}$ in diameter cannot be accurately detected by available imaging techniques [49-51]. In one study, $55 \%$ of the metastatic lymph nodes were $5 \mathrm{~mm}$ or less in diameter [52]. The lack of correlation between lymph node size and metastatic infiltration has been reported in studies of other solid tumors [5357]. Therefore, differentiating between benign and metastatic lymph nodes may be unreliable when lymph node size is used as a criterion [52]. Lymph node metastasis of EGC is still predicted by means of the presence or absence of certain tumor characteristics postoperatively $[19,43,58]$.

It is very difficult for conventional transabdominal US to visualize the gastric cancer without any assistant because of the interference of gas in the stomach (Figures $1 \mathrm{~A}, 2 \mathrm{~A}$ ). Although the likelihood of detecting gastric cancer followed by oral contrast agent exist (Figures 1 B, 2 B), the sensitivity of diagnosis of LNM of EGC by oral contrast-enhanced ultrasonography is still very low (Figure 1 B), with a rate of $33.3 \%$ in our study.

Double contrast-enhanced ultrasonography could be considered as a valid method to evaluate the microcirculatory perfusion of gastric cancer using intravenous contrast agents, based on taking an oral ultrasonic agent. An oral ultrasonic agent which was composed by a kind of soya derivative has some contribution for this study, such as the how to evacuate the air in stomach and distend the gastric lumen for displaying the lesions prominently. After taking the oral contrast agent, the stomach lumen appeared as an iso-echoic homogenous acoustic window, and its effect was superior to
Table I. The sensitivity, specificity, and Youden's index of oral contrast-enhanced ultrasonography (CEUS) and double contrast-enhanced ultrasonography (DCUS) in detecting lymph node metastasis

\begin{tabular}{|lccc|}
\hline & $\begin{array}{c}\text { Sensitivity } \\
{[\%]}\end{array}$ & $\begin{array}{c}\text { Specificity } \\
{[\%]}\end{array}$ & $\begin{array}{c}\text { Youden's } \\
\text { index }\end{array}$ \\
\hline Oral CEUS & 33.3 & 98.4 & 0.317 \\
\hline DCUS & 86.7 & 60.7 & 0.474 \\
\hline
\end{tabular}

water because the evacuation was slow. SonoVue, a microbubble contrast material with a mean diameter of $2.5 \mu \mathrm{m}$, is a blood pool agent that does not cross into the interstitial space $[59,60]$.

Because such microbubbles flow with red blood cells, the injected microbubbles act as markers for tissues that are densely populated with vessels, thereby, suggesting that angiogenesis is the foundation for tumor enhancement [61, 62]. Angiogenesis is important for tumor growth and metastasis [63-65]. Angiogenesis is an unfavorable factor related to LNM in EG [66]. Double contrastenhanced ultrasonography can be used to assess vascularity and the biological behavior of gastric carcinomas in vivo [67].

Because of this finding, we sought to predict the LNM in EGC preoperatively using DCUS by means of certain primary tumor characteristics. Although the specificity decreased from $98.4 \%$ with oral contrast-enhanced ultrasonography to $60.7 \%$ with DCUS $(p<0.005)$, the sensitivity was improved from $33.3 \%$ with oral contrast-enhanced ultrasonography to $86.7 \%$ with DCUS ( $p<0.005$ ). Because the presence of LNM has a strong adverse influence on the prognosis of patients with EGC [11,

Table II. The relationship between different clinicopathological characteristics and the rate of lymph node metastasis as well as the contrast-enhanced intensity

\begin{tabular}{|c|c|c|c|c|c|c|}
\hline Factors & Node negative & Node positive & Value of $p$ & $\begin{array}{c}\text { Marked } \\
\text { hyperenhancement }\end{array}$ & $\begin{array}{c}\text { Unmarked } \\
\text { hyperenhancement }\end{array}$ & Value of $p$ \\
\hline Age [years] & $61.0 \pm 13.5$ & $57.7 \pm 10.3$ & 0.382 & $58.5 \pm 10.9$ & $58.2 \pm 11.1$ & 0.887 \\
\hline Male & 9 & 39 & \multirow[t]{2}{*}{0.777} & 21 & 27 & \multirow[t]{2}{*}{0.260} \\
\hline Female & 6 & 22 & & 16 & 12 & \\
\hline Upper & 2 & 2 & \multirow[t]{3}{*}{0.291} & 2 & 2 & \multirow[t]{3}{*}{0.446} \\
\hline Middle & 2 & 8 & & 3 & 7 & \\
\hline Lower & 11 & 51 & & 32 & 30 & \\
\hline $\begin{array}{l}\text { Tumor } \\
\text { diameter }[\mathrm{mm}]\end{array}$ & $31.4 \pm 9.6$ & $30.8 \pm 12.0$ & 0.866 & $35.4 \pm 13.1$ & $26.8 \pm 7.80$ & 0.001 \\
\hline Mucosa & 4 & 32 & \multirow[t]{2}{*}{0.073} & 14 & 22 & \multirow[t]{2}{*}{0.105} \\
\hline Submucosa & 11 & 29 & & 23 & 17 & \\
\hline \multicolumn{7}{|l|}{ Histological type: } \\
\hline Differentiated & 5 & 39 & \multirow[t]{2}{*}{0.032} & 16 & 28 & \multirow[t]{2}{*}{0.012} \\
\hline Undifferentiated & 10 & 22 & & 21 & 11 & \\
\hline
\end{tabular}


$22,68-70]$, the high sensitivity of diagnosis is more important. The agreement of this diagnosis is very good $(\kappa$ value $=0.89)$.

Intratumor microvessel density (MVD) is a reliable index of tumor angiogenesis [71]. Many previous studies of gastric carcinoma have demonstrated that angiogenesis is one of the crucial factors for tumor development and progression in gastric cancer [72, 73]. Angiogenesis is closely correlated with biological behaviors, degree of differentiation, and metastatic lymphadenopathy in gastric cancer [74]. Contrastenhanced intensity has a strong positive linear correlation with MVD in gastric carcinoma [67]. Therefore, contrast-enhanced intensity is a promising index to evaluate the growth and progression of gastric carcinoma. This study demonstrates that depth of tumor size and degree of differentiation both relate to contrast-enhanced intensity $(p<0.05)$, which indicates that contrastenhanced intensity can be used to assess the biological behavior of EGC in vivo. We found that degree of differentiation was significantly associated with LNM $(p<0.05)$, similar to that indicated by other authors $[18,19,75]$.

Although contrast enhanced ultrasonography can assess whether LNM is present in the patients with DCUS, the location and number of lymph nodes cannot be determined. Further studies are required to evaluate LNM with precise quantitative analysis.

In conclusion, DCUS shows promise as a new noninvasive, convenient, and repeatable method to evaluate LNM in EGC and the prognosis of EGC preoperatively. Identification of EGC with marked hyperenhancement allows closer postoperative follow-up and possibly the use of drugs targeted for the growth of new vessels to prevent recurrence.

\section{Acknowledgments}

This study was supported by grants from Science and Technology Bureau of Wenzhou, Zhejiang province, China, Foreign Cooperation Foundation (H20060039). We thank all the surgeons, pathologists and the technicians at the $2^{\text {nd }}$ Affiliated Hospital of Wenzhou Medical College.

\section{References}

1. Gentsch HH, Groitl H, Giedl J. Results of surgical treatment of early gastric cancer in 113 patients. World J Surg 1981; 5: 103-7.

2. Green PH, O'Toole KM, Weinberg LM, Goldfarb JP. Early gastric cancer. Gastroenterology 1981; 81: 247-56.

3. Hochwald SN, Brennan MF, Klimstra DS, Kim S, Karpeh MS. Is lymphadenectomy necessary for early gastric cancer? Ann Surg Oncol 1999; 6: 664-70.

4. Machado G, Davies JD, Tudway AJ, et al. Superficial carcinoma of the stomach. Br Med J 1976; 2: 77-9.

5. Maehara Y, Kakeji Y, Oda S, Takahashi I, Akazawa K, Sugimachi K. Time trends of surgical treatment and the prognosis for Japanese patients with gastric cancer. $\mathrm{Br}$ J Cancer 2000; 83: 986-91.

6. Sue-Ling HM, Martin I, Griffith J, et al. Early gastric cancer: 46 cases treated in one surgical department. Gut 1992; 33: 1318-22.

7. Ikeda Y, Saku M, Kawanaka H, et al. Prophylactic lymph node dissection for early gastric cancer invading submucosa. Hepatogastroenterology 2004; 51: 887-90.

8. Roviello F, Rossi S, Marrelli D, et al. Number of lymph node metastases and its prognostic significance in early gastric cancer: a multicenter Italian study. J Surg Oncol 2006; 94 . 275-80.

9. Shan J, Chen J, Wang S. Recurrence of early gastric cancer. Zhonghua Yi Xue Za Zhi 1996; 76: 750-2.

10. Borie F, Plaisant N, Millat B, Hay JM, Fagniez PL. Appropriate gastric resection with lymph node dissection for early gastric cancer. Ann Surg Oncol 2004; 11: 512-7.

11. Sano T, Sasako M, Kinoshita T, Maruyama K. Recurrence of early gastric cancer. Follow-up of 1475 patients and review of the Japanese literature. Cancer 1993; 72: 3174-8.

12. Yasuda K, Adachi Y, Shiraishi N, Inomata M, Takeuchi H, Kitano S. Prognostic effect of lymph node micrometastasis in patients with histologically node-negative gastric cancer. Ann Surg Oncol 2002; 9: 771-4.

13. Gotoda T, Yanagisawa A, Sasako M, et al. Incidence of lymph node metastasis from early gastric cancer: estimation with a large number of cases at two large centers. Gastric Cancer 2000; 3: 219-25.

14. Jentschura D, Heubner C, Manegold BC, Rumstadt B, Winkler M, Trede M. Surgery for early gastric cancer: a European one-center experience. World J Surg 1997; 21: 845-8.

15. Roder JD, Bottcher K, Busch R, Wittekind C, Hermanek D, Siewert JR. Classification of regional lymph node metastasis from gastric carcinoma. German Gastric Cancer Study Group. Cancer 1998; 82: 621-31.

16. Isozaki H, Tanaka N, Okajima K. General and specific prognostic factors of early gastric carcinoma treated with curative surgery. Hepatogastroenterology 1999; 46: 1800-8.

17. Okamura T, Tsujitani S, Korenaga D, et al. Lymphadenectomy for cure in patients with early gastric cancer and lymph node metastasis. Am J Surg 1988; 155: 476-80.

18. Shen L, Huang Y, Sun M, Xu H, Wei W, Wu W. Clinicopathological features associated with lymph node metastasis in early gastric cancer: analysis of a singleinstitution experience in China. Can J Gastroenterol 2009; 23: 353-6.

19. Xu Y, Huang BJ, Sun Z, Lu C, Liu YP. Risk factors for lymph node metastasis and evaluation of reasonable surgery for early gastric cancer. World J Gastroenterol 2007; 13: 5133-8.

20. Guadagni S, Reed PI, Johnston BJ, et al. Early gastric cancer: follow-up after gastrectomy in 159 patients. $\mathrm{Br}$ J Surg 1993; 80: 325-8.

21. Hanazaki K, Wakabayashi M, Sodeyama H, et al. Surgical outcome in early gastric cancer with lymph node metastasis. Hepatogastroenterology 1997; 44: 907-11.

22. Kim JP, Hur YS, Yang HK. Lymph node metastasis as a significant prognostic factor in early gastric cancer: analysis of 1,136 early gastric cancers. Ann Surg Oncol 1995; 2: 308-13.

23. Maehara Y, Okuyama T, Oshiro T, et al. Early carcinoma of the stomach. Surg Gynecol Obstet 1993; 177: 593-7.

24. Ranaldi R, Santinelli A, Verdolini R, Rezai B, Mannello B, Bearzi I. Long-term follow-up in early gastric cancer: 
evaluation of prognostic factors. J Pathol 1995; 177: 343-51.

25. Hyung WJ, Cheong JH, Kim J, Chen J, Choi SH, Noh SH. Application of minimally invasive treatment for early gastric cancer. J Surg Oncol 2004; 85: 181-5.

26. Yoshikawa T, Tsuburaya A, Kobayashi O, Sairenji M, Motohashi H, Noguchi Y. Indications of limited surgery for gastric cancer with submucosal invasion - analysis of 715 cases with special reference to site of the tumor and level 2 lymph nodes. Hepatogastroenterology 2003; 50: 1727-30.

27. Brennan MF. Current status of surgery for gastric cancer: a review. Gastric Cancer 2005; 8: 64-70.

28. Abe N, Mori T, Takeuchi H, et al. Laparoscopic lymph node dissection after endoscopic submucosal dissection: a novel and minimally invasive approach to treating earlystage gastric cancer. Am J Surg 2005; 190: 496-503.

29. Chavez Rossell M. Endoscopic treatment of early gastric cancer: from endoscopic mucosal resection (EMR) to endoscopic submucosal dissection (ESD). Rev Gastroenterol Peru 2005; 25: 76-92.

30. Gotoda T. A large endoscopic resection by endoscopic submucosal dissection procedure for early gastric cancer. Clin Gastroenterol Hepatol 2005; 3: S71-3.

31. Gotoda T, Yamamoto H, Soetikno RM. Endoscopic submucosal dissection of early gastric cancer. J Gastroenterol 2006; 41: 929-42.

32. Hirasaki S, Tanimizu M, Nasu J, Shinji T, Koide N. Treatment of elderly patients with early gastric cancer by endoscopic submucosal dissection using an insulated-tip diathermic knife. Intern Med 2005; 44: 1033-8.

33. Ishikawa S, Togashi A, Inoue $M$, et al. Indications for EMR/ESD in cases of early gastric cancer: relationship between histological type, depth of wall invasion, and lymph node metastasis. Gastric Cancer 2007; 10: 35-8.

34. Kato M. Endoscopic submucosal dissection (ESD) is being accepted as a new procedure of endoscopic treatment of early gastric cancer. Intern Med 2005; 44: 85-6.

35 . Ono $\mathrm{H}$. Endoscopic submucosal dissection for early gastric cancer. Chin J Dig Dis 2005; 6: 119-21.

36. Akahoshi K, Chijiiwa Y, Hamada S, et al. Endoscopic ultrasonography: a promising method for assessing the prospects of endoscopic mucosal resection in early gastric cancer. Endoscopy 1997; 29: 614-9.

37. Halpert RD, Feczko PJ. Role of radiology in the diagnosis and staging of gastric malignancy. Endoscopy 1993; 25: $39-45$.

38. Neumaier CE, Cittadini G, Grasso A, Dahmane M. Role of ultrasonography in the staging of gastrointestinal neoplasms. Semin Surg Oncol 2001; 20: 86-90.

39. Polkowski M, Palucki J, Wronska E, Szawlowski A, Nasierowska-Guttmejer A, Butruk E. Endosonography versus helical computed tomography for locoregional staging of gastric cancer. Endoscopy 2004; 36: 617-23.

40. Tsendsuren T, Jun SM, Mian XH. Usefulness of endoscopic ultrasonography in preoperative TNM staging of gastric cancer. World J Gastroenterol 2006; 12: 43-7.

41. Yun M, Lim JS, Noh SH, et al. Lymph node staging of gastric cancer using (18)F-FDG PET: a comparison study with CT. J Nucl Med 2005; 46: 1582-8.

42. Noguchi Y, Imada T, Matsumoto A, Coit DG, Brennan MF. Radical surgery for gastric cancer. A review of the Japanese experience. Cancer 1989; 64: 2053-62.

43. Li C, Kim S, Lai JF, et al. Risk factors for lymph node metastasis in undifferentiated early gastric cancer. Ann Surg Oncol 2008; 15: 764-9.

44. Nuernberg D, Ignee A, Dietrich CF. Current status of ultrasound in gastroenterology - bowel and upper gastrointestinal tract - part 1. Z Gastroenterol 2007; 45: 629-40.

45. Byrt T, Bishop J, Carlin JB. Bias, prevalence and kappa. J Clin Epidemiol 1993; 46: 423-9.

46. Cuschieri A, Fayers P, Fielding J, et al. Postoperative morbidity and mortality after D1 and D2 resections for gastric cancer: preliminary results of the MRC randomised controlled surgical trial.The Surgical Cooperative Group. Lancet 1996; 347: 995-9.

47. Wanebo HJ, Kennedy BJ, Winchester DP, Fremgen A, Stewart AK. Gastric carcinoma: does lymph node dissection alter survival? J Am Coll Surg 1996; 183: 616-24.

48. Fukuya T, Honda H, Hayashi $T$, et al. Lymph-node metastases: efficacy for detection with helical CT in patients with gastric cancer. Radiology 1995; 197: 705-11.

49. Baba H, Maehara Y, Okuyama T, et al. Lymph node metastasis and macroscopic features in early gastric cancer. Hepatogastroenterology 1994; 41: 380-3.

50. Kurihara N, Kubota T, Otani Y, et al. Lymph node metastasis of early gastric cancer with submucosal invasion. Br J Surg 1998; 85: 835-9.

51. Nakahara K, Tsuruta O, Tateishi $\mathrm{H}$, et al. Extended indication criteria for endoscopic mucosal resection of early gastric cancer with special reference to lymph node metastasis - examination by multivariate analysis. Kurume Med J 2004; 51: 9-14.

52. Monig SP, Zirbes TK, Schroder W, et al. Staging of gastric cancer: correlation of lymph node size and metastatic infiltration. AJR Am J Roentgenol 1999; 173: 365-7.

53. Dworak O. Number and size of lymph nodes and node metastases in rectal carcinomas. Surg Endosc 1989; 3 : 96-9.

54. Herrera-Ornelas L, Justiniano J, Castillo N, et al. Metastases in small lymph nodes from colon cancer. Arch Surg 1987; 122: 1253-6.

55. Kerr KM, Lamb D, Wathen CG, Walker WS, Douglas NJ. Pathological assessment of mediastinal lymph nodes in lung cancer: implications for non-invasive mediastinal staging. Thorax 1992; 47: 337-41.

56. Kotanagi H, Fukuoka T, Shibata $Y$, et al. The size of regional lymph nodes does not correlate with the presence or absence of metastasis in lymph nodes in rectal cancer. J Surg Oncol 1993; 54: 252-4.

57. Okuda I, Kokubo T, Udagawa H, et al. Mediastinal lymph node metastasis from esophageal carcinoma: CT assessment with pathologic correlation. Nippon Igaku Hoshasen Gakkai Zasshi 1997; 57: 391-4.

58. Kwee RM, Kwee TC. Predicting lymph node status in early gastric cancer. Gastric Cancer 2008; 11: 134-48.

59. Schneider M. SonoVue, a new ultrasound contrast agent. Eur Radiol 1999; 9 Suppl 3: S347-8.

60. Schneider M, Arditi M, Barrau MB, et al. BR1: a new ultrasonographic contrast agent based on sulfur hexafluoride-filled microbubbles. Invest Radiol 1995; 30: 451-7.

61. Brasch RC, Weinmann HJ, Wesbey GE. Contrast-enhanced NMR imaging: animal studies using gadolinium-DTPA complex. AJR Am J Roentgenol 1984; 142: 625-30.

62. Strich G, Hagan PL, Gerber KH, Slutsky RA. Tissue distribution and magnetic resonance spin lattice relaxation effects of gadolinium-DTPA. Radiology 1985; 154: 723-6.

63. Folkman J. What is the evidence that tumors are angiogenesis dependent? J Natl Cancer Inst 1990; 82: 4-6.

64. Folkman J, Watson K, Ingber D, Hanahan D. Induction of angiogenesis during the transition from hyperplasia to neoplasia. Nature 1989; 339: 58-61. 
65. Song ZJ, Gong P, Wu YE. Relationship between the expression of iNOS, VEGF, tumor angiogenesis and gastric cancer. World J Gastroenterol 2002; 8: 591-5.

66. Xiangming C, Hokita S, Natsugoe S, et al. Angiogenesis as an unfavorable factor related to lymph node metastasis in early gastric cancer. Ann Surg Oncol 1998; 5: 585-9.

67. Shiyan L, Pintong $\mathrm{H}$, Zongmin $\mathrm{W}$, et al. The relationship between enhanced intensity and microvessel density of gastric carcinoma using double contrast-enhanced ultrasonography. Ultrasound Med Biol 2009; 35: 1086-91.

68. Park DJ, Lee HK, Lee HJ, et al. Lymph node metastasis in early gastric cancer with submucosal invasion: feasibility of minimally invasive surgery. World I Gastroenterol 2004; 10: 3549-52.

69. Shiu MH, Moore E, Sanders M, et al. Influence of the extent of resection on survival after curative treatment of gastric carcinoma. A retrospective multivariate analysis. Arch Surg 1987; 122: 1347-51.

70. Tanaka M, Ono H, Hasuike N, Takizawa K. Endoscopic submucosal dissection of early gastric cancer. Digestion 2008; 77 Suppl 1: 23-8.

71. Fukumura D, Jain RK. Role of nitric oxide in angiogenesis and microcirculation in tumors. Cancer Metastasis Rev 1998; 17: 77-89.

72. Carmeliet P, Jain RK. Angiogenesis in cancer and other diseases. Nature 2000; 407: 249-57.

73. Liekens S, De Clercq E, Neyts J. Angiogenesis: regulators and clinical applications. Biochem Pharmacol 2001; 61 253-70.

74. Nakajima Y, Gotanda T, Uchimiya $\mathrm{H}$, et al. Inhibition of metastasis of tumor cells overexpressing thymidine phosphorylase by 2-deoxy-L-ribose. Cancer Res 2004; 64: 1794-801.

75. Gotoda T, Sasako M, Ono H, Katai H, Sano T, Shimoda T. Evaluation of the necessity for gastrectomy with lymph node dissection for patients with submucosal invasive gastric cancer. Br J Surg 2001; 88: 444-9. 